\title{
The use of score for neonatal acute physiology perinatal extention II (SNAPPE II) in predicting neonatal outcome in neonatal intensive care unit
}

\author{
Mia RA, Risa Etika, Agus Harianto, Fatimah Indarso, Sylviati M Damanik
}

\begin{abstract}
Background Scoring systems which quantify initial risks have an important role in aiding execution of optimum health services by predicting morbidity and mortality. One of these is the score for neonatal acute physiology perinatal extention (SNAPPE), developed by Richardson in 1993 and simplified in 2001. It is derived of 6 variables from the physical and laboratory observation within the first 12 hours of admission, and 3 variables of perinatal risks of mortality.

Objectives To assess the validity of SNAPPE II in predicting mortality at neonatal intensive care unit (NICU), Soetomo Hospital, Surabaya. The study was also undertaken to evolve the best cut-off score for predicting mortality.

Methods Eighty newborns were admitted during a four-month period and were evaluated with the investigations as required for the specifications of SNAPPE II. Neonates admitted $>48$ hours of age or after having been discharged, who were moved to lower newborn care $<24$ hours and those who were discharged on request were excluded. Receiver operating characteristic curve (ROC) were constructed to derive the best cut-off score with Kappa and McNemar Test.

Results Twenty eight (35\%) neonates died during the study, 22 $(82 \%)$ of them died within the first six days. The mean SNAPPE II score was $26.3 \pm 19.84$ (range $0-81$ ). SNAPPE II score of the nonsurvivors was significantly higher than the survivors (42.75 \pm 18.59 vs $17.4 \pm 14.05 ; P=0.0001)$. SNAPPE II had a good performance in predicting overall mortality and the first-6-days mortality, with area under the ROC 0.863 and 0.889 . The best cutoff score for predicting mortality was 30 with sensitivity $81.8 \%$, specificity $76.9 \%$, positive predictive value $60.0 \%$ and negative predictive value $90.0 \%$.

Conclusions SNAPPE II is a measurement of illness severity which correlates well with neonatal mortality at NICU, Soetomo Hospital. The score of more than 30 is associated with higher mortality [Pediatr Indones 2005;45:241-245].
\end{abstract}

Keywords: neonatal mortality, SNAPPE II, NICU

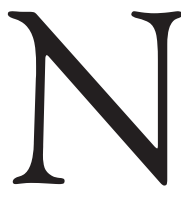

eonatal mortality is an increasingly important public health issue in developing countries. Neonatal deaths account for nearly $64 \%$ of all infant deaths. ${ }^{1}$ Indonesian Health Demography Survey in 1997 reported that neonatal mortality accounts for 22 per 1000 live births and $71.3 \%$ of them were neonates with ages less than 7 days. $^{2}$ Advances in neonatal intensive care have significantly increased survival and decreased morbidity and mortality among infants admitted at neonatal intensive care units (NICU). There are, however, significant variations in outcomes among NICUs which might reflect variations in the effectiveness of current neonatal care technology. ${ }^{3-5}$ Therefore, to increase efficiency of NICU, the development of a measurement for the severity of illness is essential to adjust the outcome

Presented at The $13^{\text {th }}$ National Child Health Congress, Bandung, Indonesia, 4-7 Juli 2005.

From the Department of Child Health, Medical School, Airlangga University, Surabaya, Indonesia.

Reprint requests to: Mia RA, MD, Neonatology Division, Department of Child Health, Medical School, Airlangga University, Soetomo Hospital, Jl. Prof. Moestopo 6-8, Surabaya 60286, Indonesia. Tel/Fax: 62-31. 5501748. 
or prognosis among neonates admitted at NICU. ${ }^{5}$

The development of illness severity indices for neonatal intensive care has lagged behind that of measures for adult and pediatric intensive care. One of these is the score for acute neonatal physiology (SNAP), developed by Richardson in 1993. The score is an organ system physiology-based illness severity index and derived from 34 routine clinical tests and vital signs within the first 24 hours of admission. ${ }^{5-7}$ SNAP perinatal extention (SNAPPE) was later developed, and provides a simple additive point score to generate mortality risks, such as birth weight, Apgar scores, and small for gestational age. ${ }^{8}$ SNAP was cumbersome to use because of the number and complexity of items. Therefore, Richardson, in 2001, simplified the score and developed second generation of SNAPPE, derived from 6 physiological variables and 3 variables of perinatal mortality risks, and also shortened the observation time from 24 hours to 12 hours of admission. ${ }^{9}$

We undertook this study to assess the validity of SNAPPE II in predicting mortality in NICU, Soetomo Hospital, Surabaya. An attempt has been made to elucidate the best cut-off SNAPPE II score for predicting mortality.

\section{Methods}

This was an observational study, conducted at NICU, Soetomo Hospital, Surabaya. The sample size calculation was 80 neonates. During a study period of four months, 80 neonates were evaluated and the necessary investigation for scoring the SNAPPE II were done within 12 hours of admission. Neonates admitted $>48$ hours of age or after having been discharged, who were released to lower newborn care less than 24 hour, and those who were discharged on request were excluded. Informed consent was given to all parents whose neonate met the inclusion criteria. This study was approved by the Hospital Ethical Committee. The variables used in SNAPPE II along with the score are given in Table 1 .

The SNAPPE II value was then calculated as the arithmetic sum of the points assigned to each of the variables. The worst score within the first 12 hours of admission was analized. The outcome measure was in-hospital mortality, divided into overall mortality $(0$ 28 days of life), first 6 days of admission mortality and
Table 1. Score for Neonatal Acute Physiology Perinatal Extention $\|^{9}$

\begin{tabular}{|c|c|c|}
\hline Variable & Measure & Point \\
\hline \multirow[t]{3}{*}{ Lowest Mean Blood Pressure } & $>29 \mathrm{mmHg}$ & 0 \\
\hline & $20-29 \mathrm{mmHg}$ & 9 \\
\hline & $<20 \mathrm{mmHg}$ & 19 \\
\hline \multirow[t]{3}{*}{ Lowest temperature } & $>35.6^{\circ} \mathrm{C}$ & 0 \\
\hline & $35-35.6^{\circ} \mathrm{C}$ & 8 \\
\hline & $<35^{\circ} \mathrm{C}$ & 15 \\
\hline \multirow[t]{4}{*}{ Ratio pO2/FiO2 } & $>2.49$ & 0 \\
\hline & $1.0-2.49$ & 5 \\
\hline & $0.3-0.99$ & 16 \\
\hline & $<0.3$ & 28 \\
\hline \multirow[t]{3}{*}{ Lowest serum $\mathrm{pH}$} & $>7.19$ & 0 \\
\hline & $7.10-7.19$ & 7 \\
\hline & $<7.10$ & 16 \\
\hline \multirow[t]{2}{*}{ Seizure } & No & 0 \\
\hline & Multiple & 5 \\
\hline \multirow[t]{3}{*}{ Urine output } & $>0.9 \mathrm{ml} / \mathrm{BW} / \mathrm{hour}$ & 0 \\
\hline & $0.1-0.9 \mathrm{ml} / \mathrm{BW} / \mathrm{hour}$ & 5 \\
\hline & $<0.1 \mathrm{ml} / \mathrm{BW} / \mathrm{hour}$ & 18 \\
\hline \multirow[t]{3}{*}{ Birth weight } & $>999 \mathrm{~g}$ & 0 \\
\hline & $750-999 \mathrm{~g}$ & 10 \\
\hline & $<750 \mathrm{~g}$ & 17 \\
\hline \multirow[t]{2}{*}{ Small for gestational age } & $>3^{\text {rd }}$ persentile & 0 \\
\hline & $<3^{\text {rd }}$ persentile & 12 \\
\hline \multirow[t]{2}{*}{ Apgar score at $5 \mathrm{~min}$} & $>7$ & 0 \\
\hline & $<7$ & 18 \\
\hline
\end{tabular}

\section{7-28 days of admission mortality.}

Mortality outcome validations used the SNAPPE II because it is the most inclusive discriminator of mortality risks (not just a physiologic illness severity score). We assessed predictive performance by the area under the curve (AUC) of the receiver operator characteristic curve (ROC). An ROC area of 1.0 indicates perfect discrimination, whereas an area of 0.5 would be completely randomized. ROC were also constructed to derive the best cut-off SNAPPE II score with Kappa and McNemar Test. All calculations were carried out with the statistical package SPSS 11.0 for Windows.

\section{Results}

During the period of 4 months, 80 neonates were evaluated and SNAPPE II were assessed. Of these 80 neonates, 64 (80\%) were in-born and 16 (20\%) were referral, 28 (35\%) neonates died during the course of the study. Table 2 gives the basic characteristics of the neonates.

The mean of SNAPPE II was 26.3 19.84 (range 0-81). The SNAPPE II of the nonsurvivals was higher significantly than the survivals $(42.75 \pm 18.59$ vs 
Table 2. Characteristics of SubJects

\begin{tabular}{lcccc}
\hline Characteristics & \multicolumn{2}{c}{ Died } & \multicolumn{2}{c}{ Alive } \\
\cline { 2 - 5 } & $\mathbf{N}(\%)$ & SD & SD \\
\hline Sex & & & & \\
$\quad$ Female & $12(33 \%)$ & & $24(67 \%)$ & \\
$\quad$ Male & $16(36 \%)$ & & $28(64 \%)$ & \\
Birth weight & & $2173 \pm 869$ & & $2675 \pm 807$ \\
$\quad<1000 \mathrm{~g}$ & $2(100 \%)$ & & $6(0 \%)$ & \\
$1000-1499 \mathrm{~g}$ & $7(54 \%)$ & & $14(74 \%)$ & \\
$1500-2499 \mathrm{~g}$ & $5(26 \%)$ & & $32(70 \%)$ & \\
$\geq 2500 \mathrm{~g}$ & $14(30 \%)$ & & & $36.42 \pm 3.01$ \\
Gestational age & & $34.96 \pm 4.38$ & $23(61 \%)$ & \\
$\quad<37$ weeks & $15(40 \%)$ & & $29(71 \%)$ & \\
$37-41$ weeks & $12(29 \%)$ & & $0(0 \%)$ & \\
$>41$ weeks & $1(100 \%)$ & &
\end{tabular}

TABLE 3. Validating of SNAPPE II IN PREDicting OVERALL MORTALITY

\begin{tabular}{ccc}
\hline SNAPPE II & Number of neonates & Death (\%) \\
\hline $0-9$ & 20 & $1(5 \%)$ \\
$10-19$ & 13 & $2(15 \%)$ \\
$20-29$ & 12 & $3(25 \%)$ \\
$30-39$ & 15 & $5(33 \%)$ \\
$40-49$ & 10 & $8(80 \%)$ \\
$50-59$ & 5 & $4(80 \%)$ \\
$60-69$ & 2 & $2(100 \%)$ \\
$>70$ & 3 & $3(100 \%)$ \\
\hline
\end{tabular}

\section{$17.4+14.05 ; \mathrm{P}=0.0001)$}

Table 3 depicts the correlation between SNAPPE II and mortality. Mortality increased with higher SNAPPE II value.

Figure 1 shows the ROC of SNAPPE II in predicting overall mortality. It shows that the discriminating ability was 0.863 . The discriminating ability of SNAPPE II in predicting the first-6-days mortality showed greater with ROC 0.889 (Figure 2). The worst performance of SNAPPE II was in predicting 7-28 days mortality, with the ROC 0.771 (Figure 3).

To evolve the best cut-off point for SNAPPE II, we looked for a score which showed optimum sensitivity, specificity, positive and negative predictive value, or if the statistic test of McNemar showed $P>0.05$ and Kappa $\leq 0.05$. The best cut-off SNAPPE II score in predicting overall mortality, on charting the ROC was 30. Sensitivity, specificity, positive and negative predictive value of score $>30$ estimating overall mortality were $78.6 \%, 76.9 \%, 64.7 \%$, and $87 \%$, respectively with McNemar Test 0.238 and Kappa 0.0001 . SNAPPE II has the best performance in pre-

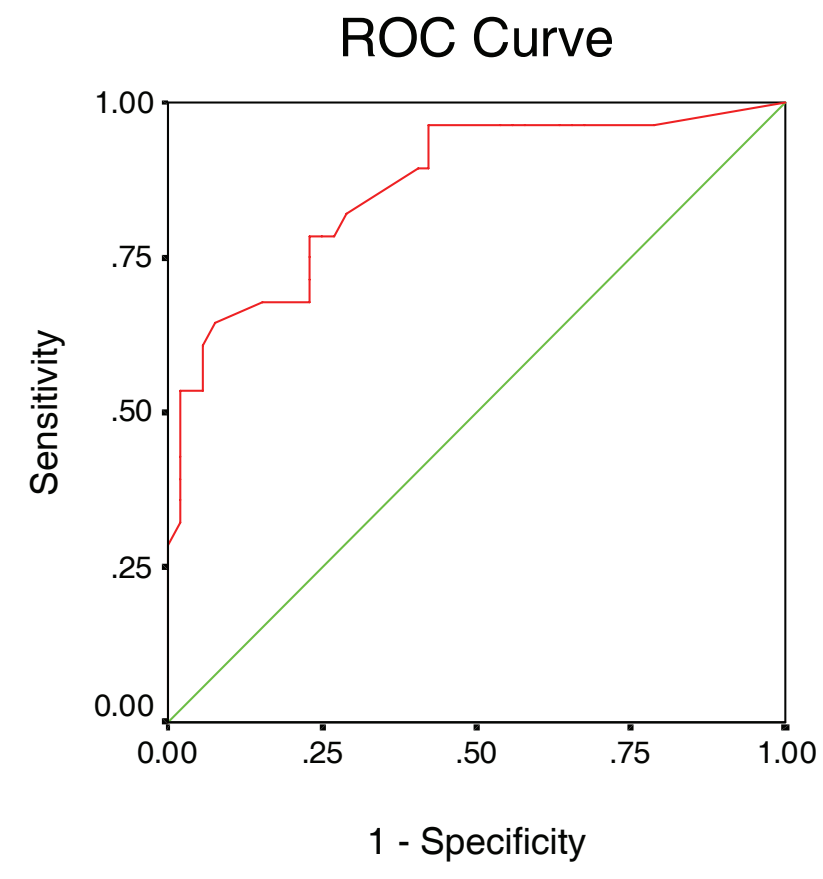

Diagonal segments are produced by ties.

Figure 1. ROC SNAPPE II IN PREDICtING OVERALL MORTALITY

dicting first-6-days mortality. The cut-off point 30 , sensitivity, specificity, positive and negative predictive value were $81.8 \%, 76.9 \%, 60 \%$ and $90.9 \%$, respectively.

\section{Discussion}

The SNAPPE II was designed primarily as a measurement of illness severity, a major but not the 
ROC Curve

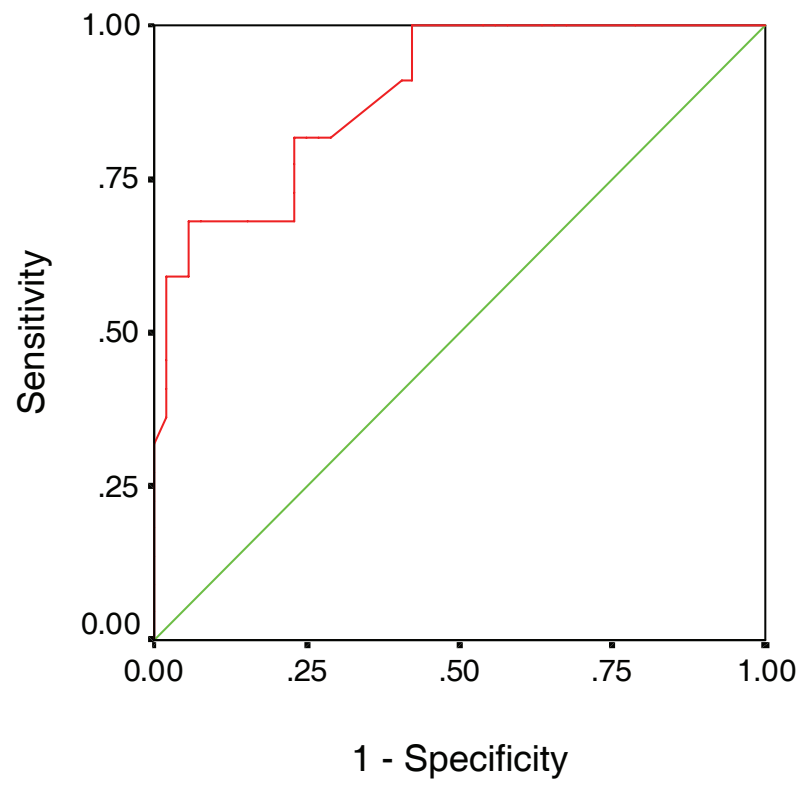

Diagonal segments are produced by ties.

FIGURE 2. ROC SNAPPE II IN PREDICTING FIRST 6 DAYS MORTALITY

only component on mortality risks. ${ }^{6}$ A prognostic score was considered valid in the population if the low score patients survive, on the contrary patients with higher score will not survive.

Our study showed that the SNAPPE II value of the nonsurvivals was higher significantly than the survivals. Overall, it correlated well with outcome with higher score predicting higher mortality. Neonates with SNAPPE II $<10$ have only a mortality of $5 \%$, but SNAPPE II $\geq 60$ was suggestive of poor outcome with mortality $100 \%$.

The ROC showed that SNAPPE II has a better performance in predicting the first-6-days mortality and overall mortality rather than the 7-28 days mortality $(0.889,0.863,0.771$, respectively). Similar observations made by Lee showed the ROC SNAPPE II in predicting first-7-days of admission mortality was $0.88 \pm 0.44$, and ROC for overall mortality was $0.75 \pm 0.52 .{ }^{10}$ Based on that data, SNAPPE II was valid and can be used in predicting mortality at NICU, Soetomo Hospital. Unfortunately, in Indonesia there was no other study to validate SNAPPE II, therefore our results can not be compared.

\section{ROC Curve}

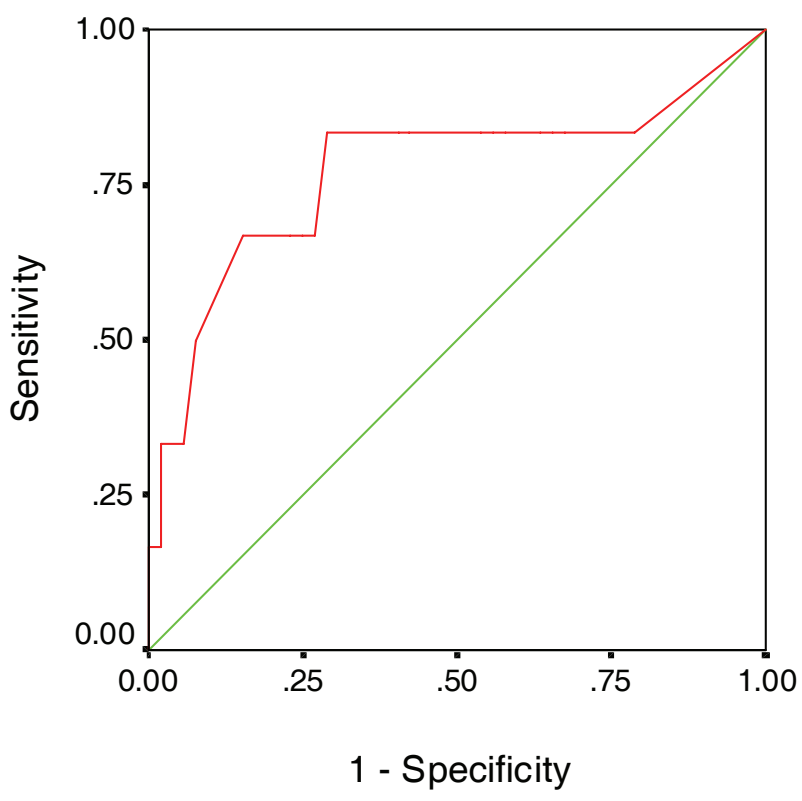

Diagonal segments are produced by ties.

Figure 3. ROC SNAPPE II IN PREDICTING 7-28 dAYS MORTALITY

A prognostic tool was considered good if it has sensitivity, specificity, positive and negative predictive value $\geq 90 \%$, or if the statistic test of $\mathrm{McNemar}$ showed $\mathrm{P}>0.05$ and Kappa $\leq 0.05$. However, studies that look for optimum value of the diagnostic test to establish the best cut-off point is very rare. Based on that, SNAPPE II scores $>30$ was considered as best cut-off point in predicting both overall mortality and first-6-days mortality.

Maiya found that SNAP scores $>10$ in VLBW babies and $>15$ in others were associated with higher mortality. ${ }^{11}$ Until now, the use of SNAP II and SNAPPE II as morbidity and mortality predictor is still being investigated and developed.

In conclusion, SNAPPE II is a measurement of illness severity and correlates well with neonatal outcome at NICU, Soetomo Hospital. SNAPPE II scores of more than 30 are associated with higher mortality.

\section{References}

1. Tripathy R, Parida SN, Tripathy SN, Devi PS, Das RN, Swain A. Physical status of newborn and neonatal outcome. Indian J Pediatr 2002;69:1041-5. 
2. Anonymous. Infeksi merupakan penyebab utama kematian neonatus muda [serial online] 2003 [cited 2003 Jun 5] Available from: URL: http://www.lin.go.id/ detail.asp? idartel $=1601033 \mathrm{KET} 0001 \&$ by $=$ topic.

3. Lee SK, McMillan DD, Ohlsson A, Pendray M, Synnes A, Whyte R, et al. Variations in practice and outcomes in the Canadian NICU network: 1996-1997. Pediatrics 2000;106:1070-9.

4. Sankaran K, Chien LY, Walker R, Seshia M, Ohlsson A, Lee SK. Variation in mortality rates among canadian neonatal intensive care units. Can Med Ass J 2002;166:173-8.

5. Richardson DK, Gray JE, McCormick MC, Workman $\mathrm{K}$, Goldman DA. Score for neonatal acute physiology: A physiology severity index for neonatal intensive care. Pediatrics 1993;91:617-23.

6. Escobar GJ, Fischer A, Li DK, Kremers R, Armstrong MA. Score for neonatal acute physiology: Validation in three kaiser permanente neonatal intensive care units. Pediatrics 1995;95:918-22.
7. Petridou E, Richardson DK, Dessypris N, MalamitsiPuchner A, Mantagos S, Nicolopoulos D, et al. Outcome prediction in Greek neonatal intensive care units using a score for neonatal acute physiology (SNAP). Pediatrics 1998;101:1037-44.

8. Richardson DK, Phibbs CS, Gray JE, McCormick MC, Workman-Daniels K, Glodman DA. Birthweight and illness severity: Independent predictors of neonatal mortality. Pediatrics 1993;91:969-75.

9. Richardson DK, Ccorcoran JD, Escobar GJ, Lee SK. SNAP-II and SNAPPE-II: Simplified newborn illness severity and mortality risk scores. J Pediatr 2001; 138:92-100.

10. Lee SK, Zupancic JAF, Pendray M, Thiessen P, Schmidt $\mathrm{B}$, Whyte R, et al. Transport risk index of physiologic stability: A practical system for assessing infant transport care. J Pediatr 2001;130:220-6.

11. Maiya PP, Nagashree S, Shaik MS. Role of score for neonatal acute physiology (SNAP) in predicting neonatal mortality. Indian J Pediatr 2001; 68:830-4. 